\title{
Perceived Stress Among Indian Children And Young Adults Living With Type 1 Diabetes During the COVID-19 Outbreak
}

Neha Agarwal ( $\square$ nagarwal88@yahoo.com )

Growth and Obesity Workforce

Mandara M Harikar

Independent Researcher

Rishi Shukla

Regency CDER, Kanpur

Anurag Bajpai

Regency CDER, Kanpur

\section{Research Article}

Keywords: COVID-19,Psychological stress,Type 1 Diabetes, Telemedicine

Posted Date: June 4th, 2020

DOI: https://doi.org/10.21203/rs.3.rs-33172/v1

License: (9) This work is licensed under a Creative Commons Attribution 4.0 International License.

Read Full License 


\section{Abstract}

Background - Strict isolation measures and interrupted healthcare services during the COVID 19 pandemic are contemplated to instigate stress universally, particularly in those with chronic illnesses such as Type 1 Diabetes (T1D).

Objective-To evaluate perceived stress towards COVID-19 among T1D individuals.

Study Design - A cross-sectional, observational study.

Participants - Adolescents and young adults (aged 10 - 25), living with T1D; and age, gender matched controls.

Interventions - An online, semi-structured survey including Perceived Stress Scale.

Outcomes - Determinants of stress and its impact on glycemic control.

Results - A total of 97 cases (49 males; mean age $18.8 \pm 4.5$ years), diagnosed with T1D (mean diabetes duration $8.0 \pm 5.0$ years; mean HBA1C $8.1 \pm 1.5 \%$ ) completed the survey. Among cases, $53.6 \%$ reported moderate stress; $41.2 \%$ low stress and $5.2 \%$ severe stress. No significant difference was observed in the mean PSS score between the cases and controls. Cases with higher PSS scores tracked pandemic-related updates with significantly lesser frequency than those with lower scores (mean rank 78.75; $p=0.01)$. High PSS score was significantly associated with HbA1C over last 6 months ( $r$ $0.276 ; p=0.015$ ) and worsened glycemic control (mean rank $63.97 p=0.012$ ).

Conclusion- An increased apprehension was seen regarding the acquisition of optimal diabetes management and care during the current infectious outbreak. Tele-medicine could emerge as an effective tool and a promising initiative to manage T1D patients during the pandemic.

\section{Introduction}

Coronavirus Disease (COVID -19), caused by a novel coronavirus SARS-CoV-2, is considered a close relative of severe acute respiratory syndrome (SARS) [1]. With the first COVID-19 case detected in December 2019 in Wuhan, Hubei province of China [2], it has spread rampantly, jeopardising health infrastructure and economies across the globe. COVID-19 was officially declared a pandemic by the World Health Organisation (WHO) on 11th March, 2020 [3].

Apart from an increased risk of mortality, COVID-19 pandemic is expected to have both short and longterm psychological consequences [4]. The desolation caused by COVID-19 is commensurate with the SARS outbreak in 2003; which was considered as a "mental health catastrophe" [5]. Adverse mental health impact has also been recorded in other epidemics, like, MERS, H1N1 and Ebola [6-8]. 
In the absence of an effective drug or vaccine against COVID-19, prevention is by far the best way to limit the infection [9]. In an attempt to mitigate the spread of the disease, an unprecedented practice of social distancing has been instituted across the nation [10]. Strict isolation measures, interruption in access to routine health care, compromised academic and social activities is contemplated to instigate stress and anxiety among all, particularly those living with chronic illnesses, such as Type 1 Diabetes (T1D) [11].

T1D is one of the most common endocrine metabolic disorders around the world [12]. Individuals living with T1D, are at an increased risk of psychological issues, owing either to the underlying disease, or due to the complexity involved in the management of diabetes [13]. Diabetes management mandates adherence to insulin, balanced diet, regular physical activity and self-monitoring of blood glucose in order to achieve good glycemic control and prevent the development of short- and long-term complications [14]

Studies have reported the psychological impact of the COVID-19 pandemic on health care workers, children and older adults [15-17]. However, data regarding the psychological impact of COVID-19 on those living with chronic illnesses such as T1D is found to be lacking.

We believe, this is the first study to analyse the level of stress among adolescents and young adults with T1D using a validated psychometric tool (Perceived Stress Scale), to identify the determinants of stress and its impact on the glycaemic control during the COVID-19 outbreak.

\section{Methodology}

This was a cross-sectional, observational study conducted across different states of India. Data was collected using an online, semi-structured questionnaire with an informed consent form preceding it. The questionnaire link was shared on social media platforms. Snowball technique was used for data collection.

Study participants included adolescents and young adults (aged 10-25 years), living with T1D; and age and gender matched controls. Those with an ability to understand English and willing to participate in the study were included. The Flesch reading ease of the questionnaire was found to be 52.9, while the FleschKincaid grade level of the questionnaire was 8.7, thereby corresponding to the reading comprehension of 8th grade students. Accordingly, for the age group of 10-14 years, parents were requested to complete the survey on their child's behalf.

Data collection was started on $30^{\text {th }}$ April 2020 at 4 PM IST and closed on $10^{\text {th }}$ May 2020 at 4 PM IST. After accepting to participate in the survey, participants were redirected to the four different sections of the questionnaire. (Appendix I).

The first section included demographic details, the second included assessment of knowledge and attitude of participants towards COVID-19 (based on the information and recommendations provided by the Ministry of Health and Family Welfare, India). Each question was awarded 1 point for the correct 
response and 0 for the incorrect response. The scores for transmission, prevention and presentation were converted to percentages.

The third section evaluated the presence of stress among the participants using the Perceived Stress Scale (PSS) and the techniques adopted to cope with stress. PSS measures the psychological stress estimated over the previous 4 weeks. It consists of 10 items measured on a five-point Likert scale ( 0 : never, 1 : almost never, 2 : sometimes, 3 : fairly often, 4:very often). The total score is obtained by adding the scores of all the items, with reverse coding for items 4, 5, 7 and 8, as they are positively stated. The total score ranges from 0 to 40 , with score 40 depicting the highest perceived stress level. There is no cutoff to differentiate between the stressed and non-stressed individual.

The fourth section included questions pertaining to T1D, trend of blood glucose levels during the outbreak, reason for poor sugar control and ways of allaying stress.

The study was approved by the Institute Ethical Committee.

\section{Statistical Analysis}

The coded data were entered and analysed using IBM Statistical Package for Social Sciences (SPSS version 25.0, SPSS, Inc., Chicago, IL, USA). Forms with incomplete data were excluded from the analysis. Continuous variables were expressed as mean (SD) and categorical variables as frequencies (percentages). The data was subjected to Shapiro-Wilk analysis to check for the normality of distribution. For non-parametric data, Mann-Whitney $\mathrm{U}$ and Kruskal-Wallis $\mathrm{H}$ test was used to analyse categorical variables, while Spearman correlation was used for continuous variables. A p-value of 0.05 was considered as significant.

\section{Results}

Of the 455 individuals invited for the survey, 451 consented to participate. Among these, 280 participants (133 males) met the age-inclusion criteria and were included in the study. For a total of 97 T1D cases, an equal number of age and gender matched participants were randomly recruited in the control group. As such, a total of 194 responses was included in the final analysis. The mean age of the 194 participants was 18.9 (4.5) years. Data was collected from all over the country with maximum representation from Uttar Pradesh (63.4\%) followed by Delhi (18.6\%). The baseline socio-demographic characteristics of the participants is depicted in Table 1.

A total of 97 adolescents and young adults [49 males; mean age 18.8 (4.5) years, diagnosed with type 1 diabetes, mean duration of diabetes 8.0 (5.0) years; mean HBA1C 8.1 (1.5)\%] completed the survey. Majority were on basal bolus regime ( $82.5 \%)$ followed by split mix regime $(12.4 \%)$ and continuous subcutaneous insulin infusion (CSII; $5.2 \%$ ).

Of the 194 participants, all had either heard or read about the COVID-19 pandemic. The prime source of information was television (72.2\%) followed by search engines, such as Google (69.1\%). Around 76.3\% (n 
$=148)$ of the participants were satisfied with the available information; with almost all (92.2\%) accessing information at least once daily.

Of the 97 cases, around $96.9 \%(n=94)$ had some information pertaining to the ways of COVID-19 transmission. Proportion of cases and controls who opted for different ways of transmission is shown in Fig.1a. A significant proportion $(77.3 \% ; n=75)$ scored more than $50 \%$ in the transmission score (i.e., they knew about two or more ways of COVID-19 transmission). No difference in the mean transmission score $\%$ was noted between the cases and control groups (Mean rank 93.18 versus $101.82 ; p=0.236$ ).

All the subjects with T1D knew about at least one of the preventive measures against COVID-19. Proportion of cases and controls who opted for different preventive measures is shown in Fig.1b. A significant proportion $(95.9 \% ; n=93)$ scored more than $50 \%$ in the preventive measures score (i.e., they knew about two or more preventive measures against COVID-19 infection). No significant difference in prevention score \% was noted between the cases and control groups (Mean rank 96.38 versus $98.62 ; \mathrm{p}=$ $0.619)$.

Around $96.9 \%$ of the cases $(n=94)$ had some knowledge regarding the symptoms of COVID-19. Proportion of cases and controls who opted for different presentations of COVID-19 is shown in Fig.1c. A considerable proportion of the participants $86.6 \%(n=84)$ scored more than $50 \%$ in the COVID-19 symptoms score (i.e., they knew about three or more symptoms of COVID-19 infection). Around $11.3 \%$ ( $n$ $=11$ ), reported to have experienced one or the other of the above symptoms over the last two weeks. A significant difference in presentation score \% was noted between the two groups (Mean rank 89.44 versus $105.56 ; p=0.04)$.

Nearly, half of all the cases $53.6 \%(n=52)$, reported moderate stress (PSS score 15-24); low stress (PSS score $0-14)$ was perceived by $41.2 \%(n=40)$ and severe stress (PSS score $25-40)$ was observed in $5.2 \%(n$ = 5); (Fig.2). There was no significant difference in the mean PSS score between cases and controls (Mean rank 101.06 versus $93.94 ; p=0.374)$. A total of $80.4 \%(n=78)$ of cases responded to the question regarding the various coping methods used to deal with stress. Nearly two-thirds of them, $74.4 \%(n=58)$ opted for talking with friends and family members as a coping measure.

Notably, cases with higher PSS scores tracked pandemic-related updates with significantly lesser frequency than those with lower stress scores (mean rank 78.75; $p=0.01$ ). A significant positive correlation was obtained between the PSS score and HBA1C level over the last 6 months $(r=0.276, p$ value $=0.015)$. No significant association with PSS score was observed for age, gender, level of satisfaction with the available information, education status, occupation, type of residence, source of information, presence of any symptom over the last 14 days, duration of diabetes or insulin regimen, as tabulated in Table 2.

Reduced frequency of monitoring of blood glucose was reported by $54.6 \%(n=53)$ of all the cases. Based on the self-monitoring of blood glucose (SMBG) over the last one month; improved glycemic control was reported by $39.2 \%(n=38)$, worsened glycemic control by $15.5 \%(n=15)$ and nearly half of them, $45.3 \%$ 
$(n=44)$ reported no change. High PSS score was observed to be significantly associated with worsened glycemic control (mean rank $63.97 p=0.012$ ), Fig.3. Of the 81 cases who answered the question regarding the challenges faced during the current pandemic, around $54.3 \%(n=44)$ reported inadequate physical activity and $51.9 \%(n=42)$ admitted to difficulty in maintaining a healthy balanced diet.

A significant proportion of the cases $(66.6 \% ; n=64)$ felt the need of easy availability of insulin and glucometer strips, online/telephonic consultations $(63.54 \% ; n=61)$ and more information regarding T1D management during the current pandemic $(52.6 \% ; n=51)$.

\section{Discussion}

The COVID-19 pandemic has emerged as a double trouble for those living with T1D. In an attempt to curb the spread of COVID-19, the Government of India announced a nation-wide lock-down on $23^{\text {rd }}$ March 2020 [10]. This much needed step taken towards the containment of the virus, has to some extent, adversely affected the availability of routine healthcare facilities, supply of drugs and medical equipment [18]. The limitation in access to health care facilities, drugs and other resources; along with the known vulnerability to infection due to a compromised immune system has left many with apprehension and increased stress levels [19].

In the present study, we found that low to moderate stress is perceived by a significant proportion (94.8\%) of individuals living with T1D. Those with higher HBA1C over preceding 6 months had higher PSS score. This could be attributed to the fact that the current pandemic, possibly, augmented their pre-existing health-related stress. Previous reports have described the negative impact of stress on the medication adherence and disease outcome [20]. A similar trend was found in our study, where severity of stress correlated negatively with adequate glycemic control. Stress and glycemic control have a bidirectional relationship. It can directly lead to disturbance in glucose regulation [21]; or can indirectly lead to nonadherence to medication and healthy lifestyles [22].

Stress leads to adoption of erratic lifestyle - including restricted physical activity and consumption of unhealthy meals $[23,24]$. In accord with this, we found that around half of our cases reported difficulty in maintaining a healthy lifestyle. This could also be attributed to the practice of self-isolation measures and restrictions imposed to curb the disease spread. People adopted different strategies to cope with stress during this outbreak. Sharing problems with friends and family members was the most common strategy adopted. This is similar to the findings reported in previous studies where participants reported increased felt need to talk with someone to vent out their distress [25].

All infectious outbreaks have their own unique set of characteristics in terms of mode of spread, type of illness caused and preventive measures to be adopted. The fear of getting infected or infecting others is a common occurrence during the infectious pandemics. Availability of adequate information to the masses is a crucial step in mitigating this fear and stress. We noted that a large proportion of cases $(76.3 \%)$ were satisfied with the information available to them. Our study showed that the majority of the participants 
obtained their information primarily through media sources. This is in agreement to previous studies which reported internet and television as prime sources of information during infectious outbreaks [26, 27]. Information provided at such platforms, in addition to providing information, also add to the level of anxiety and stress [28]. We noted significantly higher COVID-19 related stress levels among those who chose not to access information more frequently than once a week. This can be explained as a plausible coping mechanism against pandemic related upheaval.

Low levels of psychosocial distress has been reported among healthcare workers; because of better knowledge and awareness towards the pandemic [29]. We found that a considerable proportion of cases scored more than $50 \%$ in the transmission, prevention and presentation scores. Knowledge regarding preventive measures among the study group was remarkably good. This is in contrast to previous studies that have reported inadequate levels of knowledge about the measures of prevention towards the pandemic among the general public [30]. The positive trend in our study could be attributed to the vigorous measures taken by the Government and the media to reinforce healthy practices and minimize misinformation. Also, most respondents in our study possessed at least high school level education and also suffered from an underlying chronic illness, thus likely to be more sensitised to such information.

Restricted mobility during the lock-down has compromised the care of T1D patients, due to disruption in follow-up visits, restricted availability of medicines and other equipment. Majority of cases expressed the need for easy availability of insulin and glucometer strips as an indispensable measure to allay their stress. Telephonic or online consultations along with the provision of specific protocols for diabetes management during the COVID-19 was also suggested by around two-thirds of the cases.

The limitation of our study is that it was designed for patients with access to smartphones and those possessing the ability to understand English. Therefore, the results of this study cannot be extrapolated across all the sections of the society.

To conclude, majority of the cases had a satisfactory level of knowledge and awareness towards the current pandemic. However, there are increased worries and apprehension among them regarding the acquisition of optimal diabetes management and care during the current infectious outbreak. Amid the focus of containing and defeating the disease, healthcare facilities might miss out on those with chronic illnesses; whose management may worsen during the pandemic. Tele-medicine could, thereby, emerge as an effective tool and a promising initiative to manage T1D patients during the pandemic. 


\section{WHAT IS ALREADY KNOWN?}

1. Infectious outbreaks are known to impact mental health adversely.

2. Those with chronic illnesses, like type 1 diabetes are more vulnerable to psychological stress.

\section{WHAT THIS STUDY ADDS?}

1. Pre-existing inadequate glycemic control correlates positively with higher Perceived Stress Scale scores.

2. Increased stress leads to worsening of glycemic control.

3. Tele-medicine could be a promising initiative to manage T1D patients during the pandemic

\section{Declarations}

Conflict Of Interest - The authors have no conflict of interest to declare

\section{References}

1. Paules $\mathrm{Cl}$, Marston HD, Fauci AS. Coronavirus infections-more than just the common cold. Jama. 2020;323:707-8.

2. Nishiura H, Jung SM, Linton NM, Kinoshita R, Yang Y, Hayashi K, Kobayashi T, Yuan B, Akhmetzhanov AR. The extent of transmission of novel coronavirus in Wuhan, China, 2020.

3. Cucinotta D, Vanelli M. WHO declares COVID-19 a pandemic. Acta bio-medica: Atenei Parmensis. 2020;91:157-60.

4. Wang H, Xia Q, Xiong Z, Li Z, Xiang W, Yuan Y, Liu Y, Li Z. The psychological distress and coping styles in the early stages of the 2019 coronavirus disease (COVID-19) epidemic in the general mainland Chinese population: A web-based survey. Plos one. 2020;15:e0233410.

5. Mak IW, Chu CM, Pan PC, Yiu MG, Chan VL. Long-term psychiatric morbidities among SARS survivors. General hospital psychiatry. 2009;31:318-26.

6. Li L, Wan C, Ding R, Liu Y, Chen J, Wu Z, Liang C, He Z, Li C. Mental distress among Liberian medical staff working at the China Ebola Treatment Unit: a cross sectional study. Health and quality of life outcomes. 2015;13:156.

7. Lau JT, Tsui HY, Kim JH, Chan PK, Griffiths S. Monitoring of perceptions, anticipated behavioral, and psychological responses related to H5N1 influenza. Infection. 2010;38:275-83.

8. Kim HC, Yoo SY, Lee BH, Lee SH, Shin HS. Psychiatric Findings in Suspected and Confirmed Middle East Respiratory Syndrome Patients Quarantined in Hospital: A Retrospective Chart 
Analysis. Psychiatry Investig. 2018;15:355-360. doi:10.30773/pi.2017.10.25.1

9. Van Bavel JJ, Baicker K, Boggio PS, Capraro V, Cichocka A, Cikara M, Crockett MJ, Crum AJ, Douglas KM, Druckman JN, Drury J. Using social and behavioural science to support COVID-19 pandemic response. Nature Human Behaviour. 2020:1-2.

10. Lancet T. India under COVID-19 lockdown. Lancet (London, England). 2020;395:1315.

11. Kretchy IA, Asiedu-Danso M, Kretchy JP. Medication management and adherence during the COVID19 pandemic: Perspectives and experiences from LMICs. Research in Social and Administrative Pharmacy. 2020 Apr 15.

12. Tuomilehto J. The emerging global epidemic of type 1 diabetes. Current diabetes reports. 2013 Dec 1;13(6):795-804.

13. Kalra S, Jena BN, Yeravdekar R. Emotional and psychological needs of people with diabetes. Indian journal of endocrinology and metabolism. 2018;22:696.

14. Donaghue KC, Marcovecchio ML, Wadwa RP, Chew EY, Wong TY, Calliari LE, et al. ISPAD Clinical Practice Consensus Guidelines 2018: Microvascular and macrovascular complications in children and adolescents. Pediatr Diabetes. 2018;19 Suppl 27:262-274.

15. Lai J, Ma S, Wang Y, Cai Z, Hu J, Wei N, Wu J, Du H, Chen T, Li R, Tan H. Factors associated with mental health outcomes among health care workers exposed to coronavirus disease 2019. JAMA network open. 2020;:e203976.

16. Banerjee D. The Impact of Covid-19 Pandemic on Elderly Mental Health. International Journal of Geriatric Psychiatry. 2020 May 4.

17. Golberstein E, Wen H, Miller BF. Coronavirus disease 2019 (COVID-19) and mental health for children and adolescents. JAMA pediatrics. 2020 Apr 14.

18. Kretchy IA, Asiedu-Danso M, Kretchy JP. Medication management and adherence during the COVID19 pandemic: Perspectives and experiences from LMICs. Research in Social and Administrative Pharmacy. 2020 Apr 15.

19. Huang Y, Zhao N. Generalized anxiety disorder, depressive symptoms and sleep quality during COVID-19 outbreak in China: a web-based cross-sectional survey. Psychiatry Research. 2020 Apr 12:112954.

20. Cohen DM, Lumley MA, Naar-King S, Partridge T, Cakan N. Child behavior problems and family functioning as predictors of adherence and glycemic control in economically disadvantaged children with type 1 diabetes: a prospective study. Journal of Pediatric Psychology. 2004 Apr 1;29(3):171-84. 
21. Landsberg L, Young JB. Sympathoadrenal system. InContemporary endocrinology 1985 (pp. 217246). Springer, Boston, MA.

22. Horii T, Momo K, Yasu T, Kabeya Y, Atsuda K. Determination of factors affecting medication adherence in type 2 diabetes mellitus patients using a nationwide claim-based database in Japan. Plos one. 2019;14(10).

23. Stults-Kolehmainen MA, Sinha R. The effects of stress on physical activity and exercise. Sports medicine. 2014 Jan 1;44(1):81-121.

24. Bieling PJ, Alden LE. Effects of an acute a-lactalbumin manipulation on mood and food hedonics in high-and low-trait anxiety individuals. Br J Clin Psychol. 1997;36:387-95.

25. Lee AA, Piette JD, Heisler M, Rosland AM. Diabetes distress and glycemic control: The buffering effect of autonomy support from important family members and friends. Diabetes care. 2018 Jun 1;41(6):1157-63.

26. Chandrasekaran N, Gressick K, Singh V, Kwal J, Cap N, Koru-Sengul T, Curry CL. The utility of social media in providing information on Zika virus. Cureus. 2017 Oct;9(10).

27. Fung IC, Duke CH, Finch KC, Snook KR, Tseng PL, Hernandez AC, Gambhir M, Fu KW, Tse ZT. Ebola virus disease and social media: a systematic review. American journal of infection control. 2016 Dec 1;44(12):1660-71.

28. Gao J, Zheng P, Jia Y, Chen H, Mao Y, Chen S, Wang Y, Fu H, Dai J. Mental health problems and social media exposure during COVID-19 outbreak. Plos one. 2020 Apr 16;15(4):e0231924.

29. Mishra P, Bhadauria US, Dasar PL, Kumar S, Lalani A, Sarkar P, Chauhan A, Godha S, Vyas S. Knowledge, attitude and anxiety towards pandemic flu a potential bio weapon among health professionals in Indore City. Przeglad epidemiologiczny. 2016;70(1):41-5.

30. Johnson EJ, Hariharan S. Public health awareness: knowledge, attitude and behaviour of the general public on health risks during the H1N1 influenza pandemic. Journal of Public Health. 2017 Jun 1;25(3):333-7.

\section{Tables}

Table 1 - Baseline Socio-Demographic Characteristics of Cases and Controls 


\begin{tabular}{|c|c|c|c|c|}
\hline Variables & Types & $\begin{array}{l}\text { Cases } \\
(n=97)\end{array}$ & $\begin{array}{l}\text { Controls } \\
(n=97)\end{array}$ & $P$ value* \\
\hline $\begin{array}{l}\text { Age } \\
\text { (y) }\end{array}$ & & $18.84(4.48)$ & $18.95(4.50)$ & 0.804 \\
\hline \multirow[t]{2}{*}{ Gender } & Male & $49(50.5 \%)$ & $48(49.5 \%)$ & \multirow[t]{2}{*}{0.886} \\
\hline & Female & $48(49.5)$ & $49(50.5 \%)$ & \\
\hline \multirow[t]{2}{*}{ Marital Status } & Married & $2(2.1 \%)$ & $2(2.1 \%)$ & \multirow[t]{2}{*}{1} \\
\hline & Unmarried & $95(97.9 \%)$ & $95(97.9 \%)$ & \\
\hline \multirow[t]{3}{*}{ Residence } & Independent House & $74(76.3 \%)$ & $68(70.1 \%)$ & \multirow[t]{3}{*}{0.6} \\
\hline & Apartment & $21(21.6 \%)$ & $27(27.8 \%)$ & \\
\hline & Hostel & $2(2.1 \%)$ & $2(2.1 \%)$ & \\
\hline \multirow[t]{5}{*}{ Education } & Less than high school & $23(24.2 \%)$ & $23(23.7 \%)$ & \multirow[t]{5}{*}{0.782} \\
\hline & High School & $8(8.4 \%)$ & $6(6.2 \%)$ & \\
\hline & Intermediate & $13(13.7 \%)$ & $17(17.5 \%)$ & \\
\hline & Graduation & $39(41.1 \%)$ & $43(44.3 \%)$ & \\
\hline & Post Graduation & $12(21.6 \%)$ & $8(8.2 \%)$ & \\
\hline \multirow[t]{4}{*}{ Occupation } & Student & $71(73.2)$ & $76(78.4 \%)$ & \multirow[t]{4}{*}{0.38} \\
\hline & Employed & $13(13.4 \%)$ & $14(14.4 \%)$ & \\
\hline & Business & $7(7.2 \%)$ & $2(2.1 \%)$ & \\
\hline & Unemployed & $6(6.2 \%)$ & $5(5.2 \%)$ & \\
\hline
\end{tabular}

$* P$-value $<0.05$ is considered significant 


\begin{tabular}{|c|c|c|c|c|}
\hline Demographic & Type & $\begin{array}{c}n \\
\text { Mean (SD) }\end{array}$ & Mean rank & $P$ value* \\
\hline Age (y) & & $18.8(4.5)$ & $r=0.139^{\#}$ & 0.175 \\
\hline \multirow[t]{2}{*}{ Gender } & Male & 49 & 43.95 & \multirow[t]{2}{*}{0.073} \\
\hline & Female & 48 & 54.16 & \\
\hline \multirow[t]{2}{*}{ Married } & Yes & 2 & 29.25 & \multirow[t]{2}{*}{0.349} \\
\hline & No & 95 & 49.42 & \\
\hline \multirow[t]{3}{*}{ Residence } & Independent house & 74 & 45.86 & \multirow[t]{3}{*}{0.14} \\
\hline & Apartment & 21 & 59.26 & \\
\hline & Hostel & 2 & 57.25 & \\
\hline \multirow[t]{5}{*}{ Education } & Less than high school & 23 & 45.72 & \multirow[t]{5}{*}{0.692} \\
\hline & High school & 8 & 42.56 & \\
\hline & Intermediate & 13 & 43.69 & \\
\hline & Graduate & 41 & 52.02 & \\
\hline & Post graduate & 12 & 55.00 & \\
\hline \multirow[t]{4}{*}{ Occupation } & Student & 71 & 46.73 & \multirow[t]{4}{*}{0.378} \\
\hline & Employed & 13 & 61.58 & \\
\hline & Business & 7 & 48.93 & \\
\hline & Unemployed & 6 & 48.67 & \\
\hline \multirow[t]{5}{*}{ Use of Information source } & Social media & 64 & 51.30 & 0.26 \\
\hline & Search Engines & 62 & 45.96 & 0.154 \\
\hline & Television & 70 & 49.37 & 0.83 \\
\hline & Print & 58 & 45.22 & 0.105 \\
\hline & Government authorized applications & 54 & 50.87 & 0.46 \\
\hline Type 1 Diabetes duration & & $8.0(5.0)$ & $-0.047^{\#}$ & 0.646 \\
\hline HbA1C (over last 6 months) & & $8.1(1.5)$ & $0.276^{\#}$ & 0.015 \\
\hline \multirow[t]{3}{*}{ Insulin regimen } & Basal bolus regimen & 12 & 56.67 & \multirow[t]{3}{*}{0.335} \\
\hline & Split mix regimen & 80 & 47.10 & \\
\hline & Continuous Subcutaneous Insulin Infusion (CSII) & 5 & 61 & \\
\hline Presence of any symptoms & Yes & 11 & 54.27 & 0.5 \\
\hline
\end{tabular}




\begin{tabular}{|l|l|l|l|l|} 
& No & 86 & 48.33 \\
\hline \multirow{5}{*}{ Satisfaction with information made available } & Yes & 74 & 45.99 & 0.1 \\
\cline { 2 - 5 } & No & 9 & 65.94 \\
\cline { 2 - 5 } & Maybe & 14 & 54 & \\
\hline \multirow{5}{*}{ Information frequency } & Never & 2 & 78.75 & 0.01 \\
\cline { 2 - 5 } & Occasionally & 7 & 70 & \\
\cline { 2 - 5 } & Daily & 60 & 42.27 \\
\cline { 2 - 5 } & Multiple times a day & 28 & 56.05 \\
\hline
\end{tabular}

*P value < 0.05 is considered significant; \# Spearman Correlation

\section{Figures}

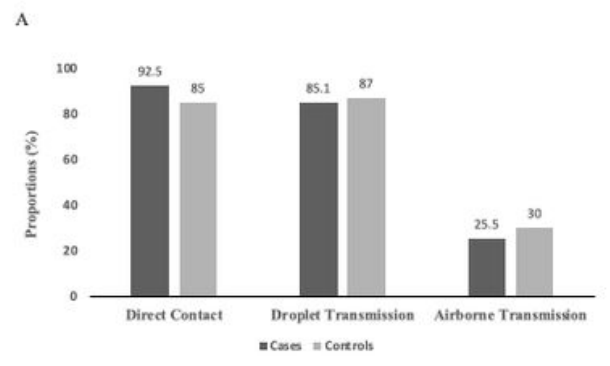

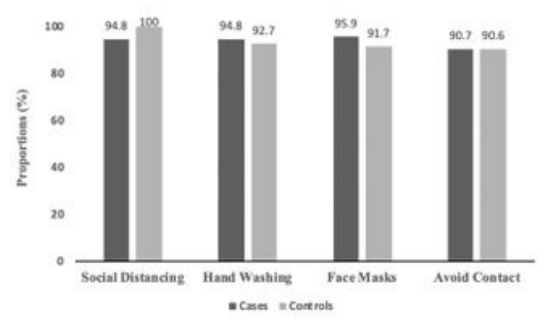

C

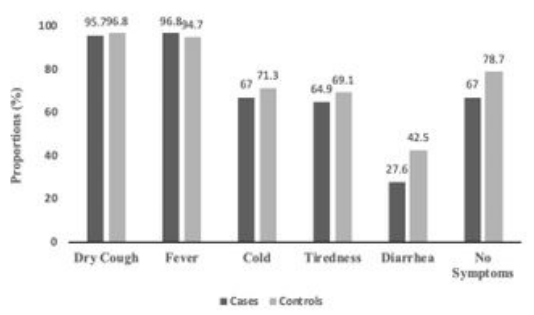

Figure 1

A) Proportion of cases and controls who opted for various modes of COVID-19 transmission B) Proportion of cases and controls who opted for various preventive measures against COVID-19 C) Proportion of cases and controls who opted for various symptoms of COVID-19 
100

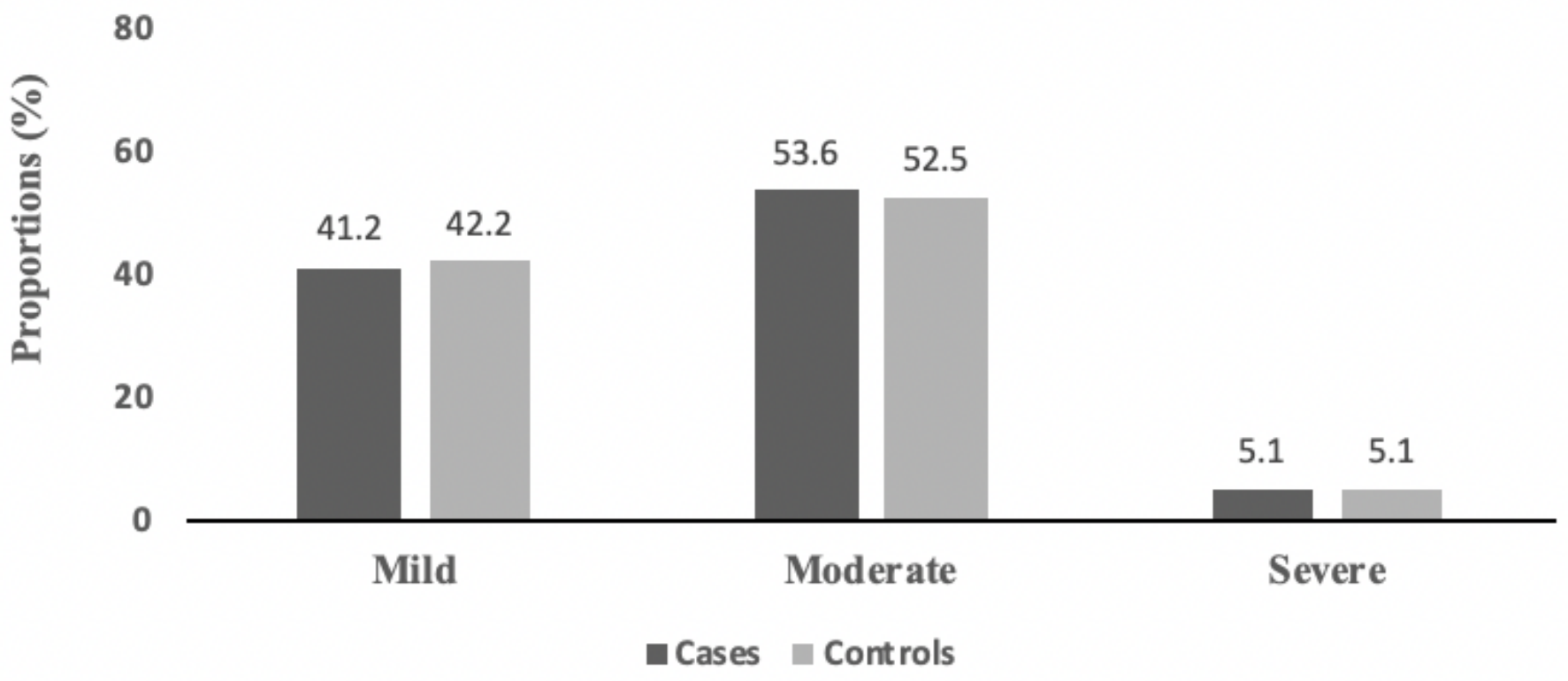

Figure 2

Proportion of cases and controls in different stress categories as per Perceived Stress Scale (PSS) score 


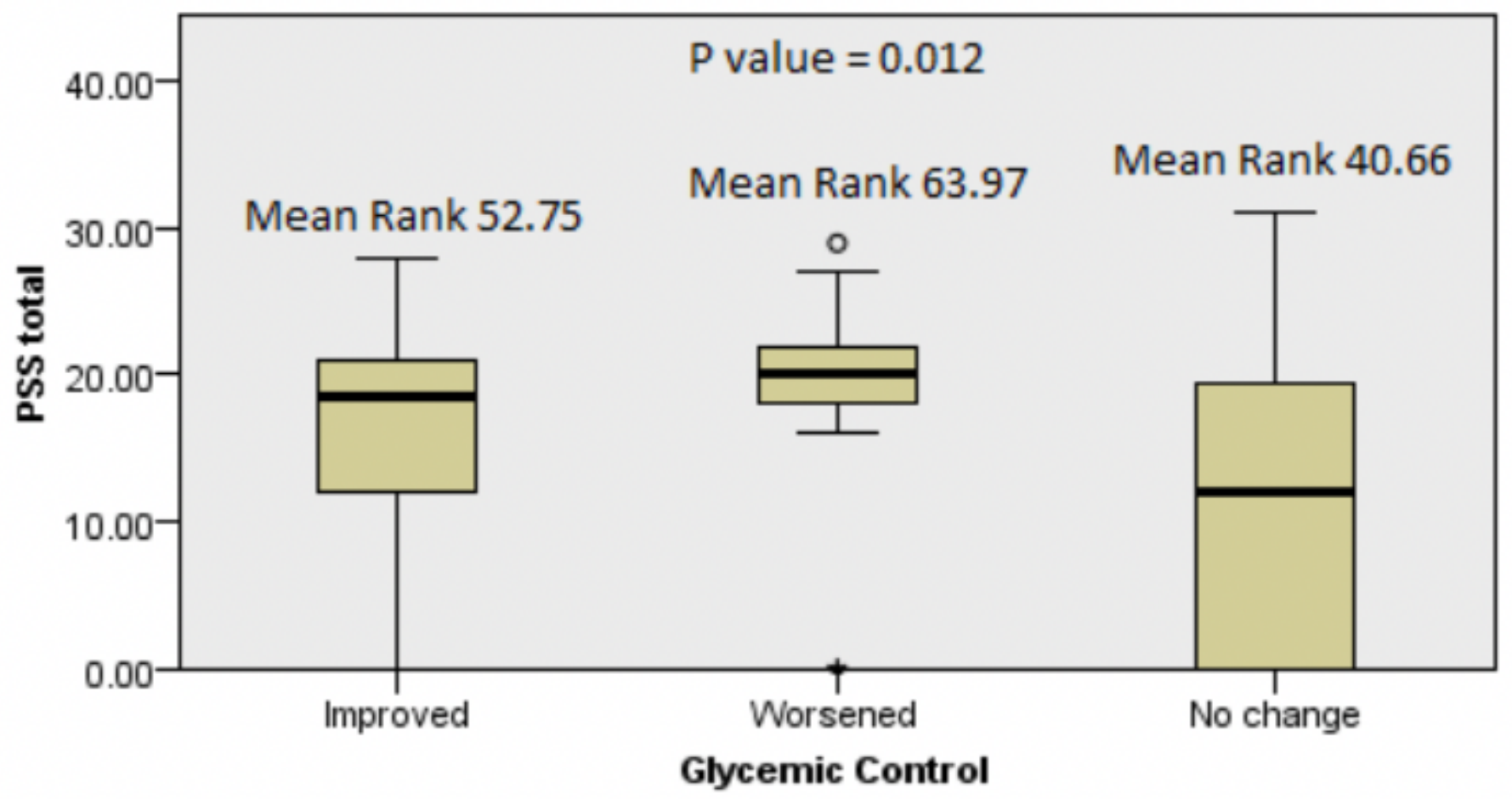

Figure 3

Variation in glycemic control with Perceived Stress Scale

\section{Supplementary Files}

This is a list of supplementary files associated with this preprint. Click to download.

- Appendix1.docx 